\title{
Structural-Phase Stabilization of Clay Materials in Hydrothermal Conditions
}

\author{
O. Sysa ${ }^{(\bowtie)}$, E. Evtushenko, I. Moreva, and V. Loktionov \\ Institute of Chemical Technology, BSTU named after V.G. Shukhov, \\ Belgorod, Russia \\ sysal975@inbox.ru
}

\begin{abstract}
The results of thermal and X-ray phase analysis of hydrothermal stabilized kaolin clay are given. An evaluation method has been suggested of crystalline structure order according to the strength degree of elementary contacts in clay suspensions. It has been noted that hydrothermal stabilization may result in crystallohydrate crystalline structure perfection, in saturation, extraction or rearrangement of water molecule in kaolinite clay structure, and influence new phase generation during ceramic material baking.
\end{abstract}

Keywords: Kaolin clay $\cdot$ Hydrothermal processing - Degree of sophistication · Crystalline $\cdot$ Structural-phase changes $\cdot$ Ceramics

\section{Introduction}

Structure imperfection often defines material quality and properties. The structure perfection for layered silicates is determined by the structure of aluminosilicate layers themselves and their positioning within crystallite. It is known that kaolinite perfect crystals are hexagonal plane particles of the regular shape which allows free sliding relative each other and providing plasticity, liquescence and close arrangement goods formation. Crystallite distortion results in distortion of kaolinite plates due to lineal and point defects. It deteriorates rheological behaviour of kaolinite suspensions, liquescency instability (Kukovskiy et al. 1966).

It is possible to affect clay material structure by several methods (natural, mechanical, chemical, biological and thermal) (Evtushenko et al. 2009). Hydrothermal clay treatment can be the most effective when it is accompanied by Rehbinder effect (adsorptive plastification) (Rebinder et al. 1972), which accelerates restructurisation and minimizes crystal defects in clay minerals for a short period of time (Evtushenko et al. 2006).

\section{Methods and Approaches}

X-ray phase material analysis has been done with a diffractometer "DRON-3". XRDpattern was shot with $\mathrm{CuK} \alpha$ filtered radiation, - radiation $(\mathrm{Ni}-$ filter); voltage across the tube is $20 \mathrm{kw}$; anode tube current is $20 \mathrm{~mA}$; measurement range is $10000-4000$ counts per second; detectors rotation rate is $2,4 \mathrm{rot} / \mathrm{min}$; angular mark is 10 . Card index 
JCPDF was used for phase identification of elementary contacts durability formed without particles in clay slurry. The calculation was done according to Ur'ev model (1972, 2002) for low aggregate suspensions (Zubehin et al. 1995):

$$
\mathrm{F}_{1}=\frac{\gamma_{m} \eta_{\min } d^{2}}{6,4}
$$

where $\gamma_{\mathrm{m}}$ is share rate corresponding to complete structural destruction, $\mathrm{s}-1$; $\eta_{\min }$ is effective viscosity corresponding to complete structural destruction, $\mathrm{Pa}$ s; $\mathrm{d}$ is average particle diameter, $\mathrm{m}$.

Differential-thermal analysis was done with a derivatograph OD-102.

\section{Results and Discussion}

Kaolin clay of local deposits has been studied, which show structural changes of clay mineral after steaming in a pressure vessel at pressure from 1 up to $4 \mathrm{MPa}$.

With X-ray phase analysis we determined constant phase clay composition before and after treatment, with significant deviations of kaolinite crystalline structure. Hydrothermal modification at saturated steam pressure up to $4 \mathrm{MPa}$ drives up crystallinity index according to Hinckley and intensivity of main diffractional kaolinite reflections (Table 1), that testifies to a greater mineral structure order in the treated raw material (Shlykov et al. 2006).

But "Hinckley crystallinity index" $\mathrm{C}_{\mathrm{h}}$ decrease depending on defects in layer composition. This parameter is not always applicable to index correlation of index characteristics with its real structure.

Basing on the said above the authors developed an estimation method of material structure sophistication degree according to the strength magnitude of elementary contact, formed between particles in clay suspensions.

Table 1. Change in "Hinckley crystallinity index" (Ch) of kaolinite after hydrothermal treatment

\begin{tabular}{l|l|l|l}
\hline $\begin{array}{l}\text { Kaoline clay } \\
\text { deposits }\end{array}$ & $\begin{array}{l}\text { Initial } \\
\text { kaoline }\end{array}$ & $\begin{array}{l}\text { Kaoline after pressure } \\
\text { treatment } \\
1,6 \mathrm{MPa}\end{array}$ & $\begin{array}{l}\text { Kaoline after pressure } \\
\text { treatment } \\
4,0 \mathrm{MPa}\end{array}$ \\
\hline Zhuravliniy Log & 0,20 & 0,22 & 0,46 \\
\hline Gluhovetskoe & 0,77 & 0,83 & 1,27 \\
\hline Kyshtymskoye & 0,55 & 0,47 & 0,61 \\
\hline Prosyanovskoye & 0,51 & 0,63 & 0,63 \\
\hline Novoselitskoye & 0,26 & 0,35 & 0,31 \\
\hline
\end{tabular}


It has been found that elementary contact strength decreases at hydrothermal treatment pressure and temperature increase by more than an order. Ranging by crystalline structure defects these kaolines can be placed as follows: Zhuravliniy Log > Glukhovetskiy > Kyshtymskiy > Prosyanovskiy and Novoselitskiy.

Some differences in endo-and exothermal processes during baking in kaoline samples depending on hydrothermal modification have been studied (Gorshkov et al. 1988). It has been determined that maximum endothermic effect of kaoline dehydration shifts towards higher temperatures that testifies to crystalline structure sophistication. Restructurisation results in additional hydration and lessening connection energy of crystal water in kaoline, facilitates water molecule extraction penetrating into basis of tetrahedral kaoline layers.

Thermal capacity change dependence of the studied materials during baking has been studied. In the temperature range $950-1020{ }^{\circ} \mathrm{C}$ there are several exothermic extreme values testifying to crystallization possibility of a variety of phase ( $\beta$-crystobalite, mullite, sillimanite, $\gamma$-alumina). Structural change of the initial material causes temperature shifts at the initial crystallization phase, as in clays with clearly seen crystalline structure mullite is formed at lower temperature and in greater quantity than from disordered structure minerals.

\section{Conclusions}

Hence it has been determined that hydrothermal treatment improves significantly stabilization of clay minerals structure as well as ceramic material baking processes, that has been proved by several research methods. Due to crystallohydrate structure change, saturation, water molecule distribution in kaolinite structure dehydration parameters change, processes take place which cause temperature shift of new phase chilling point in the interval of lower temperatures.

Acknowledgement. The work is realized in the framework of the Program of Flagship University development on the base of the Belgorod State Technological University named after V.G. Shukhov, using equipment of High Technology Center at BSTU named after V.G. Shukhov.

\section{References}

Evtushenko EI, Sysa OK (2006) Structural modification of clay raw material in hydrothermal conditions. University news. North-Caucasian region. Technical sciences series, no 2, pp 8286

Evtushenko EI, Sysa OK, Moreva IYu, Bedina VI, Trunov Y (2009) Raw material preparation refining during activation processes in ceramics technology. Glass Ceram 1:15-16

Gorshkov VS, Saveliev VG, Fedorov NF (1988) Physical chemistry of silicates and other highmelting compounds. High School, Moscow

Kukovskiy Y (1966) Structure peculiarities and physic-chemical properties of clay minerals. Naukova Dumka, Kiev 
Rebinder PA, Ur'ev NB, Shukin Y (1972) Physic-chemical mechanics in chemical technology of disperse systems. Theor Bases Chem Technol 6:16-24

Shlykov VG (2006) X-ray analysis of disperse soils mineral composition. GEOS, Moscow

Zubehin AP, Strakhov VI, Chekhovskiy VG (1995) Physico-chemical research methods of highmelting non-metal and silicate materials. Synthesis, Saint-Petersburg

Open Access This chapter is licensed under the terms of the Creative Commons Attribution 4.0 International License (http://creativecommons.org/licenses/by/4.0/), which permits use, sharing, adaptation, distribution and reproduction in any medium or format, as long as you give appropriate credit to the original author(s) and the source, provide a link to the Creative Commons license and indicate if changes were made.

The images or other third party material in this chapter are included in the chapter's Creative Commons license, unless indicated otherwise in a credit line to the material. If material is not included in the chapter's Creative Commons license and your intended use is not permitted by statutory regulation or exceeds the permitted use, you will need to obtain permission directly from the copyright holder. 